\title{
Pl\|R
}

\section{HEALTH AND HUMAN SCIENCES}

\section{The Effect of Time on Consumers' Image of the Gulf Coast after the Deepwater Horizon Oil Spill}

Student researcher: Julia Branstrator, Senior

Consumers' image of a destination plays a crucial role in the travel industry. Some researchers, including Asli D. A. Tasci and William C. Gartner in their 2007 study "Destination Image and Its Functional Relationships," relate the importance of proper image development to the overall success of a destination in tourism. The purpose of this research was to examine the impact of the Deepwater Horizon oil spill on tourism destinations on the Gulf of Mexico. The study examined the impact of time on consumers' perceptions of Gulf destinations in the year following the spill. A convenience sample technique was used for the survey. The student population surveyed represented an important target market for the Gulf: spring break travelers. A paper survey was distributed to undergraduate students with majors in hospitality and tourism management, computer graphics technology, and dietetics. Ninety-nine valid responses were analyzed to answer three questions. First, is the Gulf of Mexico still appealing? Second, what is the change in consumers' image since the oil spill? Third, is there a difference between perceptions of the "Gulf Region" as a whole and specific destination on the Gulf Coast? Students ranked destinations on the Gulf in their top 5 destinations to visit for spring break, indicating it was still appealing. After one year, students' image of Gulf destinations improved significantly. The results from the third question pointed out that students associated common beach destinations in Florida with the Gulf of Mexico, but did not realize the exact geography of a destination, affecting their perception of the region. These results provided important insight for crisis management by destinations.

Research advisor Jonathon Day comments, "The economic recovery of tourism destinations following a disaster is closely tied to consumers' image of the region. As this and other studies show, for a variety of reasons the recovery of the tourism sector in the Gulf Region has been faster than expected in most locations." 